\section{Cell sister}

\section{Michael R. Hanley}

Neuron. Editors Zach W. Hall, A. J. Hudspeth and Louis F. Reichardt. Cell Press, 50 Church Street, Cambridge, Massachusetts 02138. 12/yr. US \$210, Europe $\$ 260$, elsewhere $\$ 235$ (institutional); US \$94, Europe $\$ 134$, elsewhere $\$ 114$ (personal).

ONE of the success stories in scientific publishing has been the emergence of the biological-science journal, Cell. Largely, if not exclusively, the vision of one individual, Benjamin Lewin, Cell has become the pre-eminent forum for full-length research papers in molecular and cell biology. It is not surprising, therefore, that the publisher has set off after new challenges. The result is Neuron, and its aim is to be the journal in neuroscience.

Neuron publishes a combination of commissioned reviews and full-length research manuscripts. Production standards are first-rate, with high-quality reproduction of gels, photomicrographs and autoradiographs. The editorial office handles submitted manuscripts efficiently, and the turnaround time from submission to publication is often within the two-to-three months ideal achieved by Cell and EMBO Journal.

To date, the original papers have been good, but not distinguished. This may, in part, be due to the inevitable problem for specialist journals of drawing the best papers away from the broad-circulation, general-interest journals. Indeed, it remains to be seen what sort of neuroscience will be published by Cell in the future. For example, much of the recent research on the developmental genetics of Drosophila eye has widespread interest for biologists, and would perhaps be blunted in its impact if it were to appear in a parochial neuroscience setting. The generality of problems in signal transduction, cell adhesion, pattern formation, transcriptional regulation of gene expression and growth control will mean that a journal such as Neuron will find it progressively harder to define what belongs to its pages. But it must be said that the editors have shown a forward-looking and insightful flexibility in recognizing that points of fundamental interest to the neuroscientist may be established in some surprising experimental systems.

I am particularly impressed with the commissioned reviews which have emerged, to my mind, as the journal's clearest strength. The topics that have been covered include creation of nervecell lines by immortalizing gene transfer, neural-crest cell lineage, retinoids and morphogenesis, long-term potentiation, regulation of growth cones and mechan- isms of trophic factors. These are some of the most exciting areas of neuroscience, and are subjects that profit from critical consideration of the larger biological context. In many cases, the articles break sufficient new ground to prompt the thought

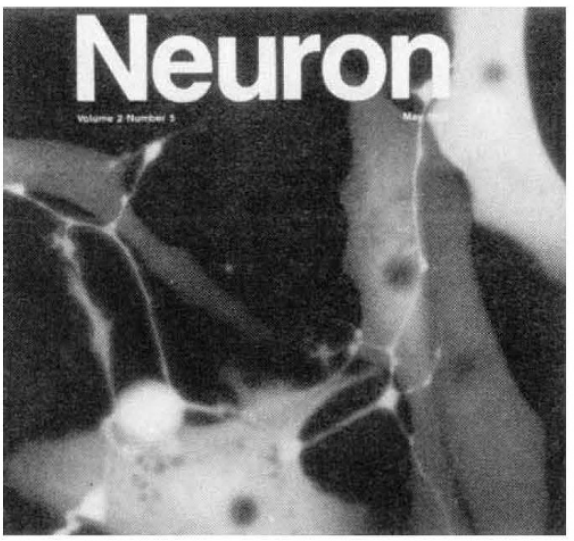

that they are a new kind of primary research publication, one devoted to ideas rather than experimental results.

These successes show the influence of a tough and effective editorial board. As with Cell, the editors and their board are drawn from the ranks of the innovative and the progressive, and the board is not

\section{Sight lines}

\section{John Cronly-Dillon}

Visual Neuroscience: An International Journal for Empirical and Theoretical Research. Editor Katherine V. Fite. Cambridge University Press. 12/yr. UK and elsewhere £182, North America $\$ 280$ (institutional); UK and elsewhere $£ 84$, North America $\$ 120$ (personal).

New journals on vision appear with almost predictable regularity. They differ little from one another in style or format, which encourages the impression that their main raison d'être is to provide further venues for publications that help the researcher in his grant applications.

Having seen the first few issues of the Journal of Visual Neuroscience, I am reassured that any reservations of that sort were, in this case, ill founded. In the first issue, the editor states that "the primary goal of Visual Neuroscience is to bring together in one journal a broad range of excellent studies that represent the diversity and originality of contemporary research and theory dealing with the neural basis of vision". On the face of it, this seems like a carte blanche invitation to authors to submit a Pandora's box of contributions, that is, until one examines the list of research areas covered by the journal - comparative visual-system studies, organization and function; developmental processes and patterns, photo- top heavy with the identikit panel of old fogeys. This may mean that Neuron will be prepared to take some risks, and it will be interesting to see if its early promise of publishing provocative and stimulating papers is fulfilled.

Inevitably, Neuron will be judged against competitors such as Journal of Neuroscience, Neuroscience or European Journal of Neuroscience. Unlike the others, Neuron is essential for any library in the biological sciences. It is also one of the few journals for which a good case can be made for individual subscription. It is realistically (though certainly not altruistically) priced, but the main reason for recommending a personal subscription is not affordability. Rather it is that Neuron, like $C e l l$, appears to be bound primarily by static electricity. Whoever conceived the binding of these journals has succeeded in making them disintegrate upon repeated photocopying. This trait of the Cell Press journals may please the publishers but annoys the scientific consumer no end. It should not be impossible to invest in a little glue.

Michael Hanley is in the MRC Molecular Neurobiology Unit, Hills Road, Cambridge CB2 $2 Q H, U K$. receptors and transduction; retinal anatomy, physiology, neurochemistry; subcortical visual pathways, visuomotor functions; thalamo-cortical pathways, visual cortex, perceptual mechanisms; and theoretical computational models.

This is a well-balanced selection of topics, which together probably represent the main thrust of research in visual neuroscience. As a place in which studies of them are brought together, the journal is likely to be extremely useful to active researchers who wish to keep their fingers on the pulse of a wide variety of related fields while dispensing a minimum of effort. In this respect it seems to me that the journal's appeal could be further improved by the periodic inclusion of an invited review article on a topic relating to one of the designated subject areas, and perhaps a regular editorial reflecting on notable developments in visual neuroscience.

A challenge for any new journal, even one that is well planned, is whether it is able to meet its declared intentions by attracting contributions which, in terms of quality, content and range of topics, fulfil its aspirations. Again, I was impressed on all three counts. If this standard can be maintained Visual Neuroscience will, I suspect, find a well-earned place on the shelf of every research worker with a serious interest in the subject.

John Cronly-Dillon is in the Department of Optometry and Vision Sciences, University of Manchester Institute of Science and Technology, Manchester M60 1QD, UK. 